\title{
CORRIGENDUM
}

\section{Similar worldwide patterns in the sex pheromone signal and response in the oriental fruit moth, Grapholita molesta (Lepidoptera: Tortricidae) - CORRIGENDUM}

\author{
A.L. Knight, W. Barros-Parada, D. Bosch, \\ L.A. Escudero-Colomar, E. Fuentes-Contreras, \\ J. Hernández-Sánchez, C. Yung, Y. Kim, O.B. Kovanci, \\ A. Levi, P. Lo, F. Molinari, J. Valls and C. Gemeno \\ doi:10.1017/S0007485314000637, Published by Cambridge University Press, 19 September 2014.
}

The Authors apologise for an error in the spelling of the author name C. Yung.

This should be C. Jung. Thus the author names should have been as follows:

A.L. Knight, W. Barros-Parada, D. Bosch, L.A. Escudero-Colomar, E. Fuentes-Contreras, J. Hernández-Sánchez, C. Jung, Y. Kim, O.B. Kovanci, A. Levi, P. Lo, F. Molinari, J. Valls and C. Gemeno.

\section{Reference}

Knight, A.L., Barros-Parada, W., Bosch, D., Escudero-Colomar, L.A., Fuentes-Contreras, E., Hernández-Sánchez, J., Yung, C., Kim, Y., Kovanci, O.B., Levi, A., Lo, P., Molinari, F., Valls, J. \& Gemeno, C. Similar worldwide patterns in the sex pheromone signal and response in the oriental fruit moth, Grapholita molesta (Lepidoptera: Tortricidae). Bulletin of Entomological Research. Published by Cambridge University Press, 19 September 2014. doi:10.1017/S0007485314000637. 